\title{
DESBORDANDO EL GÉNERO Y EL SEXO
}

\section{Overflowing Gender and Sex}

\author{
Claudia Truzzoli \\ c.truzzoli@gmail.com \\ Centro de análisis de Programas Sanitarios - España
}

Recibido: 28-02-2017

Aceptado: 20-04-2016

\section{Resumen}

Ni el género ni la sexualidad se dejan encorsetar dentro de unas normas que informan cómo deben ser y actuar hombres y mujeres para ser reconocidos socialmente como normales. Tanto el género como el sexo son susceptibles de desbordamiento de dichos encuadres rígidos, porque tal desbordamiento responde a lo real vivenciado por cualquier hombre o mujer. Las normas son un constructo artificial que no responde a la auténtica identidad genérica y sexual de cada sujeto, que es mucho más compleja que el reduccionismo monolítico que quiere demarcar la diferencia entre masculino y femenino. Dicha separación tan tajante no puede explicar la coexistencia de ambas características en un mismo sujeto ni las pretensiones de los transgéneros de ser considerados con una identidad que desmiente su sexo biológico, ni la angustia de los transexuales convencidos de estar atrapados en un cuerpo equivocado.

Palabras Clave: Género, sexo, identidad de género, feminismo, heterosexualidad, transgéneros, transexuales.

\begin{abstract}
Neither gender nor sexuality is allowed to be curtailed within norms that inform how men and women should be and act to be socially recognized as normal. Both gender and sex are susceptible to overflowing of such rigid frames, because such an overflow responds to the real thing experienced by any man or woman. Norms are an artificial construct that does not respond to the authentic generic and sexual identity of each subject, which is much more complex than the monolithic reductionism that wants to demarcate the difference between male and female. Such a clear separation can not explain the coexistence of both characteristics in the same subject nor the claims of transgenders to be considered with an identity that belies their biological sex, nor the anguish of transsexuals convinced to be trapped in a wrong body.
\end{abstract}

Keywords: Gender, sex, gender identity, feminism, heterosexuality, transgenders, transsexuals. 
Estamos tan habituados a dar por sentado afirmaciones acerca de la identidad de género y la identidad sexual que pasan por verdades incuestionadas pero que la realidad vivencial de quienes las sostienen no se deja encuadrar en definiciones tan simples y monolíticas. Dos grandes movimientos sociales, el feminismo por una parte y los movimientos de liberación homosexual por otra, han puesto el énfasis en las falsedades e inconsistencias de cierto esencialismo conservador que guiado por la necesidad de defender los supuestos patriarcales y el heterosexismo confluyen en sostener que ser hombre y ser mujer son consecuencia de una causalidad biológica que orientaría a cada género a sentirse cómodo con su identidad y predeterminado a sentirse sexualmente atraído por el sexo contrario al suyo. Así, cada género según esta concepción naturalista, estaría definido por aptitudes y actitudes que serían las que le permitirían reconocerse como tal porque estarían restringidas a su propio género sin integrar características atribuidas al género contrario. Si además agregamos que, según esta manera de entender la diferencia sexual, hombres y mujeres deberían sentirse atraídos sexualmente por una causalidad biológica, dejaría sin explicar aquellas identidades que no coinciden con estas definiciones tanto en género como en orientación sexual, a menos que se las calificara como patologías o desviaciones anormales.

Hay una militancia -inconfesada por inconsciente- que hace del heterosexismo una orientación sexual que se adueña del concepto de normalidad como también de las características genéricas que se cierran de manera monolítica a incluir cualquier rasgo atribuido al otro género dentro del propio. Adrienne Rich, importantísima poeta americana, ya denunciaba en su texto "Heterosexualidad obligatoria y existencia lesbiana", este hecho. También existe una cerrazón dentro de algunos grupos de homosexuales a negar la intromisión en su subjetividad de otros deseos ajenos a su homosexualidad. ¿Pero esto responde a las vivencias reales de los sujetos portadores de tales identidades? ¿Quién puede considerarse hombre o mujer? No puede contestarse esta pregunta sin referirse a las normas preestablecidas que la cultura en la que se vive indica para reconocerse como tal. Las normas en ese sentido, son espejos donde mirarse para contrastar el propio sentimiento de sí mismo/a, y una manera de constatar en qué medida la propia identidad se adecua o no a esas prescripciones. El problema surge cuando las personas no se sienten representadas en las normas que las definen como hombres o como mujeres. Sexo y género no siempre están en sintonía. Suponerlo, sólo es un artificio que pretende en nombre de una supuesta normalidad reducir la identidad sexuada a un esencialismo biológico que no puede explicar la múltiple realidad del género vivenciado que no se ajusta exactamente al ideal normativo.

Han sido necesarios años de lucha para que la homosexualidad fuera descatalogada de los manuales psiquiátricos como una enfermedad. Incluso en ciertas corrientes conservadoras dentro del mismo psicoanálisis se sigue considerando la homosexualidad como una perversión, olvidando que como tal no constituye una estructura, como lo son la neurosis, la psicosis y la perversión, sino una preferencia objetal que puede estar presente en esas distintas estructuras, lo que definiría el carácter neurótico, psicótico o perverso de dicha orientación según en qué 
estructura psicológica operara. Lo que significa que no se puede hablar de la homosexualidad como una patología en sí misma, sin tener en cuenta la estructura psicológica del sujeto que es homosexual. Puede ser un síntoma en un sujeto normal o bien una elección que responde a un verdadero deseo del sujeto, que sólo será considerado patológico por la ideología heterosexista dominante que define de manera tajante lo que considera normal y excluye cualquier diferencia que no se ajuste a sus parámetros. Pero si esto aún se debate en torno a la homosexualidad, ¿qué decir de aquellos casos más cuestionadores de estas identidades fijas como sucede en el transgenerismo y la transexualidad? Y para complejizar aún más el panorama, algo tan poco plausible de ser cuestionado como el sexo biológico, resulta que hay casos que demuestran hasta qué punto en la determinación del mismo sexo biológico, intervienen criterios normativos que se imponen, por ejemplo, en aquellos casos de no coincidencia del sexo anatómico con el cromosómico o en el caso de los intersexuales. ¿Qué explicación se da para estos casos? Las diferentes respuestas son coherentes con los valores que las distintas ideologías quieren defender.

El esencialismo biológico sostiene que es la naturaleza, que con sus hormonas crea un sexo anatómico que será sostenido por una identificación con el género que le corresponde a esa anatomía y una orientación sexual hetero. Pero nada en estas cuestiones es tan simple como se quiere creer. La identificación con el otro género en el transgenerismo, la sensación de estar preso/a en el cuerpo equivocado en la transexualidad, la preferencia sexual por el mismo sexo, la dificultad de poder establecer un sexo determinado en casos de intersexualidad o de no coincidencia del sexo anatómico con el sexo cromosómico, han sido y son desafíos para el esencialismo biológico, que para ser coherente con sus tesis trató de explicar estas desviaciones de la norma como patologías que había que corregir y para las que se propusieron terapias adecuadas a ese fin. No es baladí que el esencialismo biológico sea sostenido por grupos conservadores que alertan contra la ideología de género como una cuestión perturbadora porque discute lo que ellos consideran como sexualidad legítima, intento que muchas declaraciones de Obispos en la actualidad llevan más lejos cuando asocian esa legitimidad a la tríada sexualidad/procreación/matrimonio monógamo y una asociación entre feminidad y maternidad como algo determinado por la naturaleza.

Si esto fuese tan simple, cómo explicar entonces los desacuerdos distónicos de quien se siente hombre o mujer, pero no se adecua a las normas que lo/a definen como tal, o los transgéneros que siendo mujeres se sienten hombres u hombres que se sienten mujeres, pero sin llegar a la radicalidad de querer cambiar su anatomía para adecuar su sensación subjetiva de género con el que es diferente de su anatomía, como es el caso de los transexuales. O la situación ambigua en la que se encuentran los intersersexuales quienes quedan a merced de criterios médicos subjetivos para asignarlos a un género determinado que implica operaciones que podrían postergarse hasta la pubertad para dar lugar al sujeto a que exprese con qué género se siente identificado. Cualquier anomalía en estas cuestiones, sea por una disforia de género, una inadecuación al mismo o una orientación sexual diferente, serán consideradas por este 
esencialismo como una desviación que se considera en casos más leves como una anomalía y en casos más radicales como una patología.

\section{Figura 1. Aydian Dowling, transexual masculino, modelo de portada de la revista masculina Men's Health}

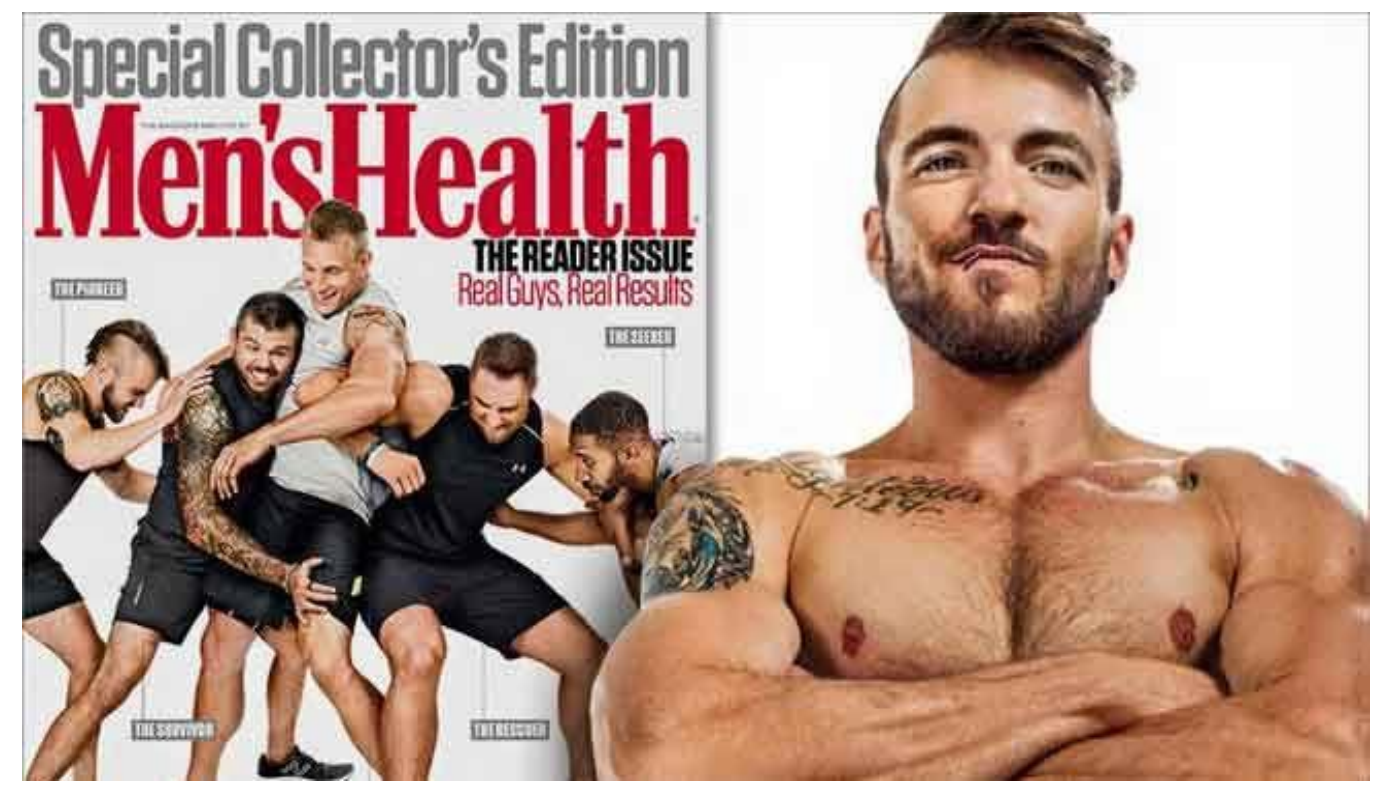

Fuente: Portada Men's Health, octubre de 2015

El pensamiento esencialista está bastante discutido por las corrientes constructivistas que sostienen que el género es una adaptación a un estilo de identidad propuesto por los primeros cuidadores en principio y luego reforzado por la cultura a la que se pertenece. Ese estilo, sin embargo, varía en distintos contextos sociales.

Por poner sólo unos ejemplos de cómo las identidades genéricas pueden ser muy flexibles, en Indonesia tienen un nombre para describir a aquellos sujetos en los que su anatomía y su identidad de género no concuerdan entre sí. En Indonesia, por ejemplo, nombran cinco géneros flexibles: la mujer femenina, llamada makkunrai, el hombre masculino, llamado oroami, la mujer masculina, llamada calabai, el hombre femenino, llamado calalai, el sacerdote transgénero, llamado bissu. En África, en el grupo étnico de los lovedú, existe el matrimonio entre mujeres, una de cuyas circunstancias para que éste se produzca es el derecho de una hija o de una hermana a reclamar para sí a otra mujer como nuera o como esposa. (Citado por Susana Narotzky en Silvia Tubert (ed), Figuras del padre. 


\section{Figura 2. Imagen de María Patiño, la mejor vallista española.}

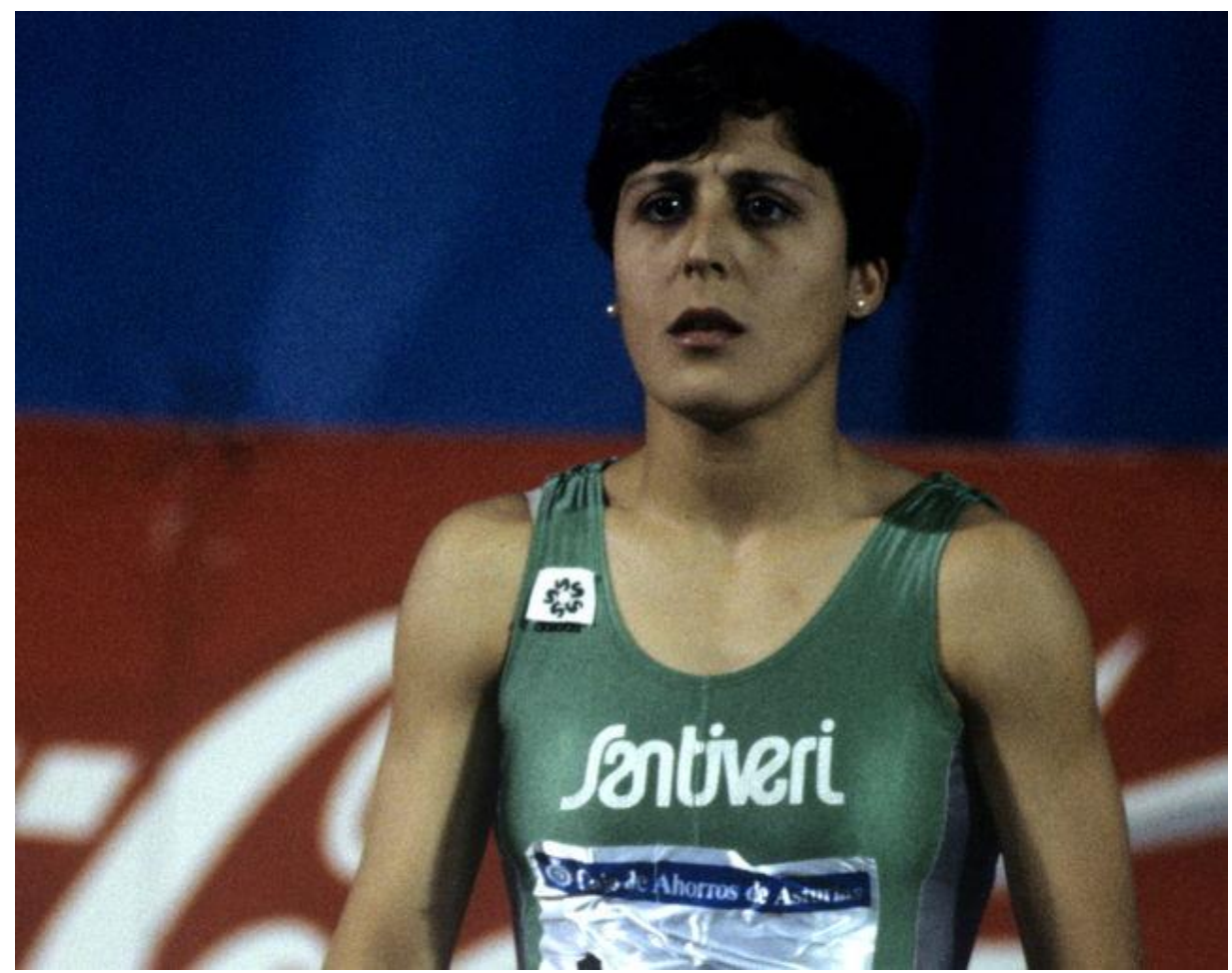

Fuente: 20minutos.es, 11 de septiembre de $2015^{1}$

A María Patiño no se le permitió participar en los juegos olímpicos de 1988 por no haber pasado el control de sexo. Las células de la cara interna de su mejilla revelaron que tenía un cromosoma Y y que sus labios vulvares ocultaban unos testículos. No tenía ni ovarios ni útero y por tanto, el COI de acuerdo a sus criterios para determinar el sexo, concluyó que no era una mujer. Esto trajo como consecuencia la prohibición de participar en el equipo femenino, la pérdida de su identidad, de su novio y un enorme trastorno en su vida personal. Hoy sabemos que hay casos de insensibilidad a los andrógenos en personas que tienen un genotipo XY y testículos funcionales pero sus células no responden a la testosterona, por lo que no sólo no desarrollan caracteres sexuales secundarios masculinos, sino que al llegar a la pubertad, a menudo responden al estrógeno producido por sus propios testículos y adquieren una voluptuosa figura femenina y una identidad de género también femenina. Por tanto, la genética cromosómica no siempre sigue las reglas que marca el sexo anatómico. Cuando alguien se mira al espejo y no se reconoce ni en sentimientos, ni en deseos ni en su propio cuerpo como hombre o mujer es alguien que no encuentra su lugar y lo expone a un gran sufrimiento.

\footnotetext{
${ }^{1}$ Disponible en: http://blogs.20minutos.es/quefuede/2015/09/11/quien-fue-ma-jose-martinez-patino-y-sulucha-por-demostrar-que-era-una-mujer/ [20/02/2017].
} 
Otro caso dramático es el de David, niño de ocho meses sometido a una intervención quirúrgica por fimosis, que sufrió en la intervención accidentalmente una cauterización de una gran parte del pene. Sus padres supieron que John Money, psicólogo neozelandés especializado en sexología, sostenía que si un niño o niña intersexo se somete a cirugía y se le socializa en un género diferente del que se le asigna al nacer, puede adaptarse perfectamente bien al nuevo género porque creía en la neutralidad del género en la primera infancia y el papel fundamental de la socialización para producir una identidad genérica. Gracias a esta información, a David se le extirparon los testículos y se recomendó que fuera criado como una chica, que en adelante se llamaría Brenda. Pero empezó a preocuparles que Brenda prefiriera jugar con pistolas y camiones y quisiera orinar de pié, por lo que le ofrecieron administrarle estrógenos, a lo que Brenda se negó como también a que se le implantara una prótesis vaginal. Prefería las actividades masculinas y no le gustaba que se desarrollaran sus pechos. Creyendo que se había cometido un error en la reasignación de género, trasladaron su caso a Milton Diamond, profesor de anatomía y biología reproductiva, que creía en la base hormonal de la identidad, que no puede ser invertida por mucha socialización que se emplee en el intento y que era suficiente que un niño intersexuado tuviera un cromosoma Y -que se suponía suficiente para la masculinidad social-, para concluir que debería ser criado como chico. Brenda pasó a ser otra vez David y a vivir como un chico a los catorce años. Se le implantó un falo entre los quince y los dieciséis años que le permitió cierto placer sexual, orinar de pié, pero limitando algunas de las funciones que se esperaban de él, lo cual hace que David entre en la norma masculina sólo de forma ambivalente. Terminó suicidándose.

Figura 3. David Reimer, imagen documental sobre su vida en la BBC

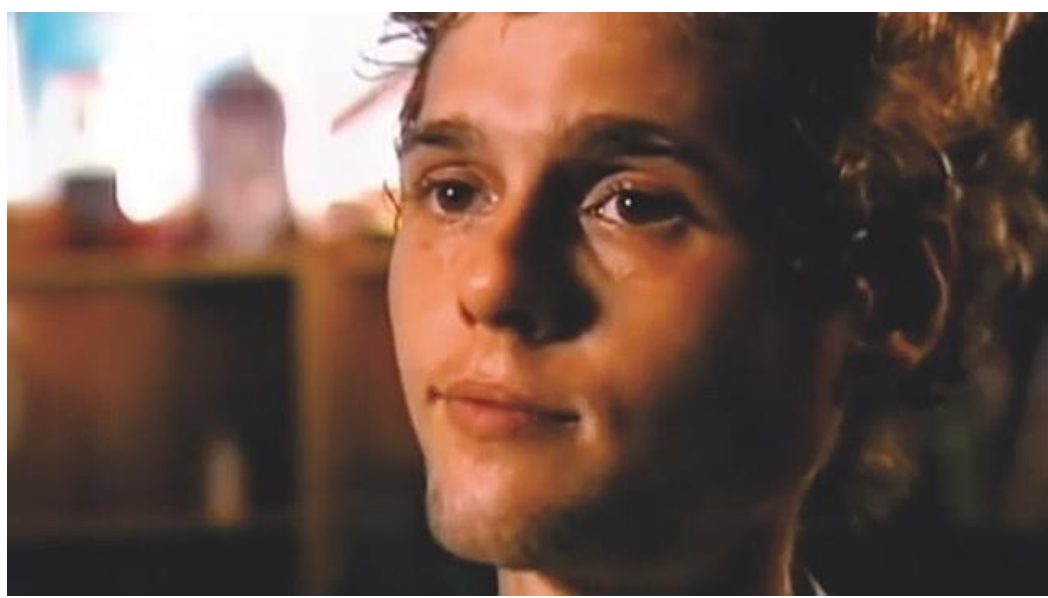

Fuente: ABC.es, 24 de agosto de $2015^{2}$

2 Disponible en: http://www.abc.es/sociedad/20150824/abci-david-reimer-experimento-sexo201508211445.html [20/02/2017]. 
Anne Fausto Sterling, doctora en filosofía y profesora de Psicología y Estudios de género, sostiene que el género es un tipo diferente de identidad y que su relación con la anatomía es compleja y se opone a cualquier cirugía coercitiva para adaptar el cuerpo a la imagen social del género escogido. John Colapinto, escritor y periodista, habla del fracaso de aquellos individuos que han sido reasignados quirúrgicamente para vivir como mujeres u hombres "normales" y "típicos" porque nunca se logra la normalidad, ya que la misma es un constructo artificial al que los sujetos intentan adaptarse sin lograrlo nunca del todo. La fantasía de transexuales de hombre a mujer que supone que a través de la reasignación de sexo lograrán una paz definitiva, se apoya en la creencia esencialista de que existe una esencia de la feminidad que ellos sienten en sí mismos y que podrían expresar ampliamente con la reasignación deseada. Constatar que sus dudas identitarias y su no estar a la altura del género que su anatomía les exige, podría explicar -en parte- porque el índice de suicidios es tan alto en la transexualidad. También es importante tener en cuenta las dificultades de la vida real que viven donde se encuentran con una transfobia importante que los expone a agresiones, muertes, dificultades para encontrar un trabajo normal que no los aboque necesariamente a la prostitución como último recurso.

Figura 4. Imagen de Brandon (a la izquierda) de la película Boys dont' cry

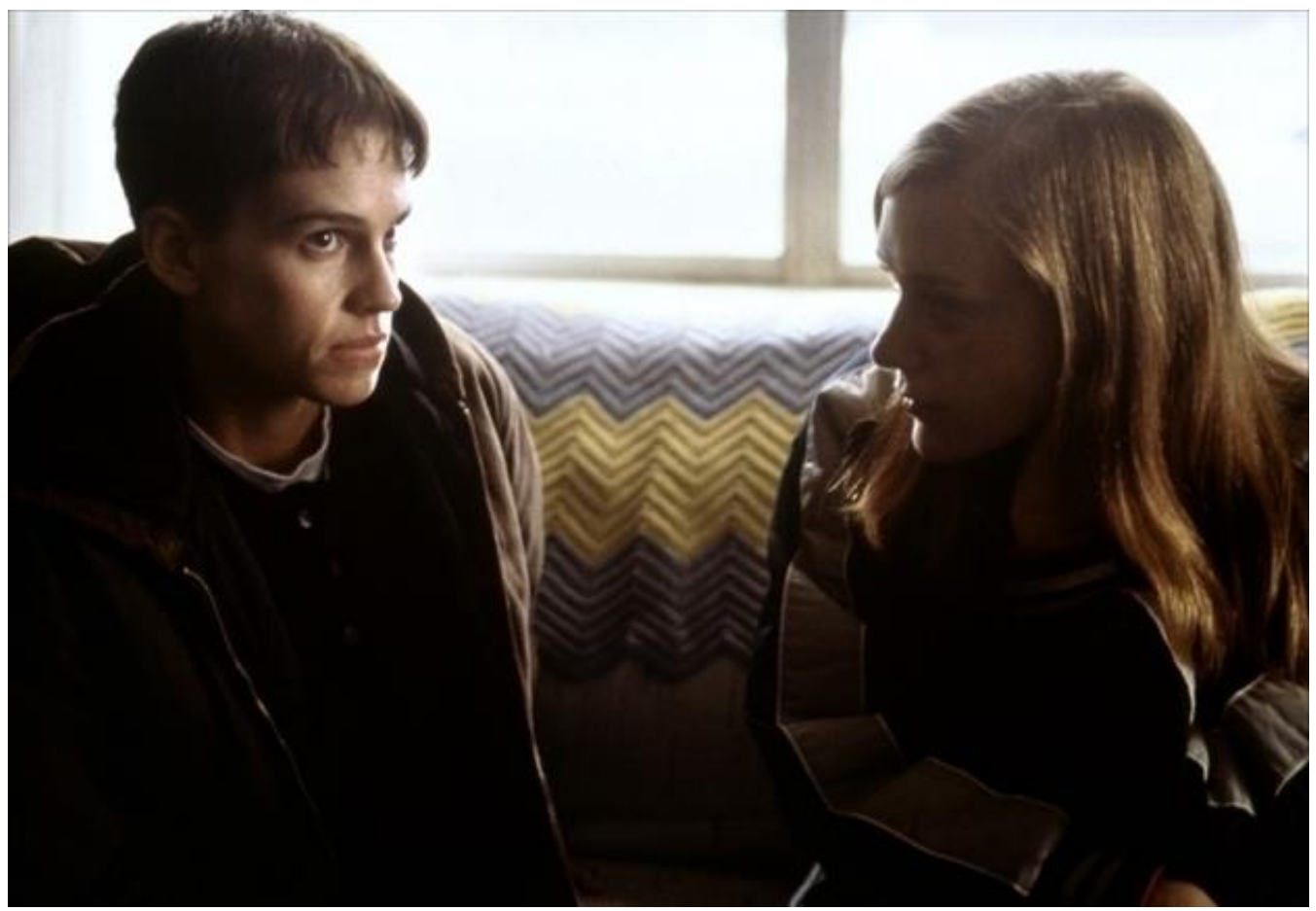

Fuente: cinenthusiat, junio de $2012^{3}$

${ }^{3}$ Disponible en: https://cinenthusiast.files.wordpress.com/2011/07/boysdontcry.jpeg [20/02/2017]. 
Una película, Boys dont' cry, nos muestra un caso de transgenerismo en una chica, Tenna, que utiliza el nombre de Brandon cuando se presenta socialmente como chico. Cuando intenta tener relaciones sexuales con una joven, le impide a ésta que le toque los genitales, pero ella descubre que él tiene los pechos vendados lo que le revela su verdadera anatomía. A pesar de ser ella heterosexual, no le impide seguir su aventura con Brandon ni la posibilidad de tener sexo lésbico. Esto nos muestra que los conceptos sociológicos del género entendidos como hombres y mujeres no se pueden reducir a la diferencia sexual anatómica ni la conducta sexual manifiesta nos informa del carácter de la orientación. La identidad no es tan sólida ni tan inmutable como quisiera pensarse, sino que a veces hay accidentes en lo real que desvelan un goce placentero y desconocido para el sujeto hasta ese momento.

Cuando en la América profunda, donde se desarrolla esta película, los amigos de la chica que está con Brandon y que la pretenden sin que ella les corresponda, descubren que Brandon, su rival, es en realidad anatómicamente una chica, la golpean salvajemente y la violan, en una mezcla de sentimientos, que van desde la venganza y la humillación porque la chica que pretendían hubiera preferido a este personaje ambiguo, que tomaron por un chico y por el peligro que representaba esa transgresión a las normas imperantes en género y sexualidad. Violarla suponía para ellos "colocarla en el lugar que le correspondía por su sexo anatómico".

\section{Figura 5. Escena de la película M Butterfly}

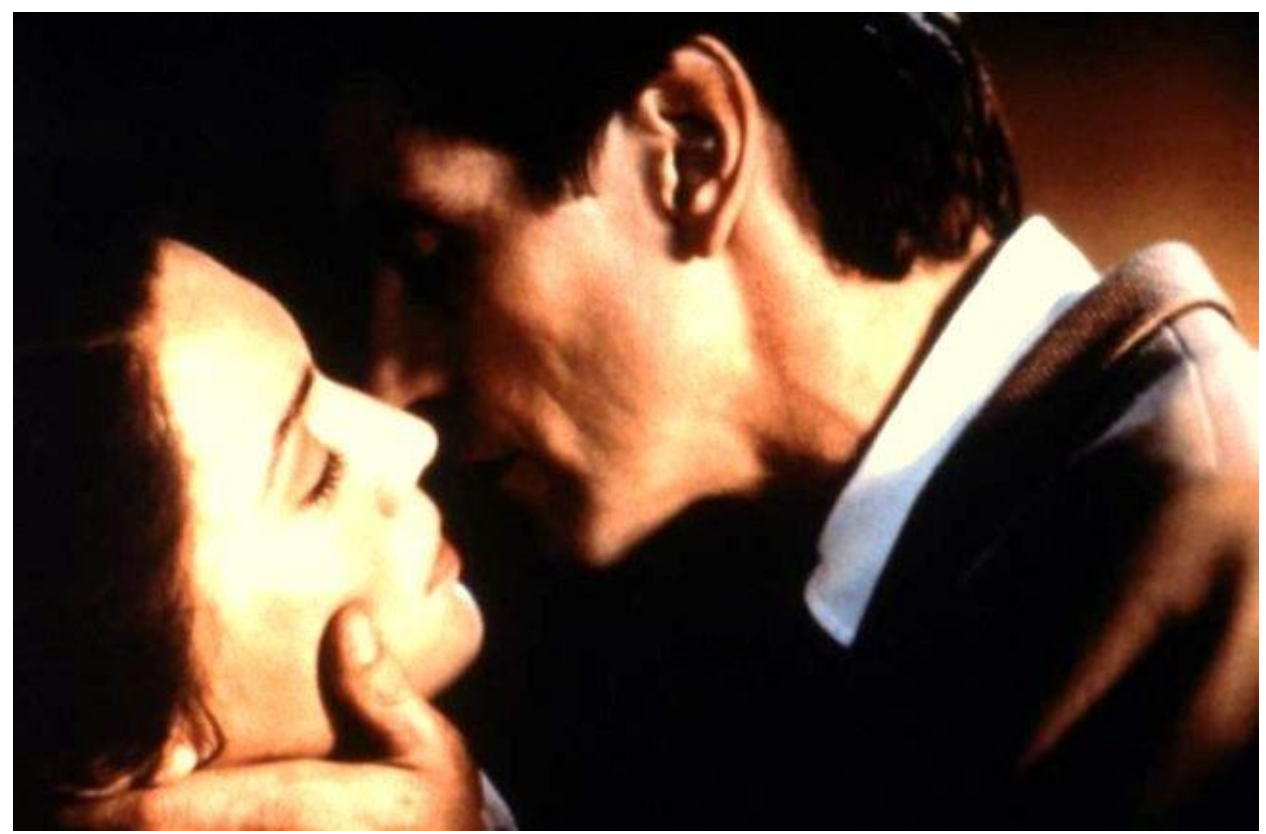

Fuente: Blog de cine, 28 de octubre de $2011^{4}$

\footnotetext{
${ }^{4}$ Disponible en: https://www.blogdecine.com/criticas/david-cronenberg-m-butterfly-la-terrible-ilusion-delamor [20/02/2017].
} 
Otro caso real, mostrado en el film M Butterfly, donde un diplomático francés mantuvo durante veinte años relaciones sexuales con un travesti creyéndola una hermosa mujer cantante de ópera, que en realidad era un hombre y un espía. ¿Sabía o no que no era una mujer? ¿O era un saber propio del fetichismo que reniega de lo sabe?

Esa relación lo lleva a la cárcel por ser acusado de complicidad en el espionaje y cuando finalmente le es revelada la identidad real de su partenaire que se presenta a visitarlo vestido como un hombre, él, enfrentado a la desmentida, no puede tolerarlo y se suicida en un acto teatral donde se trasviste él mismo como mujer.

Como Judith Butler nos recuerda gracias a sus conocimientos de psicoanálisis, “aacaso podemos llamar heterosexual a quien simplemente tiene conductas sexuales con el otro sexo sin tener en cuenta su fantasía, lo que lo erotiza, las circunstancias por las cuales se emparejó con su partenaire? Por ejemplo, ¿el hombre que empuja a su mujer a vincularse con otro hombre no está fantaseando un encuentro potencialmente homosexual que queda suspendido pero que en realidad está enviando al otro hombre algún aspecto de sí mismo que el otro también recibe a través de la mujer que se intercambia? En este sentido, ¿los celos heterosexuales extremados no están determinados por un potencial homosexual no reconocido en el celoso? ¿Se enfurece por la infidelidad de su mujer o porque ella ha podido realizar con otro hombre lo que a él le está prohibido? Gracias al psicoanálisis, podemos comprender no sólo el funcionamiento de la construcción de la fantasía y su papel en el deseo sexual sino también que la sexualidad nunca puede ser totalmente capturada por ninguna regla, más bien se caracteriza por su desplazamiento que emerge de improviso en un campo de restricciones, que, si bien la limitan, impulsan el deseo trasgresor. Según escribe Freud en Las pulsiones y sus destinos, hay una dimensión de nosotros mismos y de nuestra relación con los otros que no podemos conocer y este no saber que nos impulsa no es ni exclusivamente biológico ni cultural sino siempre el lugar de su densa convergencia." 


\section{BIBLIOGRAFÍA}

- Benjamin, Harry (1966): The transsexual phenomenon. New York: The Julien Press, INC Publishers

- Butler, Judith (2006): Deshacer el género. Barcelona: Ediciones Paidós Ibérica S.A.

- Colapinto, John (2000): As nature made him. The boy was raised as a girl. New York: Harper Collins.

- Diamond, Milton y Beh, Hazel Glenn (2008): "Changes in management of children with intersex conditions". En: Nature Clinical Practice: Endocrinology \& Metabolism, vol. 4, nº 1, pp. 4-5.

- Freud, Sigmund (1908): "Las fantasías histéricas y su relación con la bisexualidad. En: Obras Completas. Volumen IX, El delirio y los sueños en la "Gradiva" de W. Jensen y otras obras (1906-1908). Buenos Aires: Amorrortu Editores, pp. 137-148.

. (1915): "Pulsiones y destinos de pulsión". En: Obras Completas. Volumen XIV, Contribución a la historia de movimiento psicoanalítico. Trabajos sobre metapsicología y otras obras (1914-1916). Buenos Aires: Amorrortu Editores, pp. 105-134.

. (1927): "Fetichismo". En: Obras Completas. Volumen XXI. El porvenir de una ilusión. El malestar de la cultura y otras obras (1927-1931). Buenos Aires: Amorrortu Editores, pp. 141152.

- Money, John y Ehrhardt, Anke (1982): Desarrollo de la sexualidad humana, diferenciación y dimorfismo de la identidad de género desde la concepción hasta la madurez. Madrid: Morata.

- Narotzky, Susana (1997): "El marido, el hermano y la mujer de la madre: algunas figuras del padre". En: Silvia Tubert (ed.): Figuras del padre. Madrid: Ediciones Cátedra, pp. 189-218.

- Rich, Adrienne (1980/2001): "Heterosexualidad obligatoria y existencia lesbiana". En: Adrienne Rich (ed.) Sangre, pan y poesía. Prosa escogida 1979- 1985. Barcelona: Icaria, pp. 4186.

- Fausto Sterling, Anne (2006): Cuerpos sexuados. Barcelona, Melusina. 